\title{
Lightweight hybrid CFRP design for machine tools with focus on simple manufacturing
}

\author{
Frederik Birk $^{1}$ (D) $\cdot$ Fares Ali $^{1} \cdot$ Matthias Weigold ${ }^{1} \cdot$ Eberhard Abele $^{1} \cdot$ Klaus Schützer $^{2}$
}

Received: 20 November 2019 / Accepted: 25 May 2020 / Published online: 28 June 2020

(C) The Author(s) 2020

\begin{abstract}
There is a continuing demand in machine tools for an increase in productivity. This can be achieved by higher speeds and process parameters, which demand structures with a high stiffness to weight ratio including the use of materials with a high specific modulus. The lack of standardized interfaces and more complex design and manufacturing process prevent the broad use of these materials. This applies especially for CFRP (carbon fiber reinforced polymer) which has the highest specific modulus compared to conventional construction materials. Due to that and the higher material damping in comparison with steel, parts out of CFRP can improve the precision of machine tools. These advantages often remain unutilized because of the challenging integration of CFRP parts. Therefore, this paper presents an innovative approach to use CFRP in a hybrid design for machine tool structures focusing on improved dynamic behavior, increased specific stiffness, and ease of manufacture.
\end{abstract}

Keywords Machine tool $\cdot$ Design $\cdot$ Composite material

\section{Introduction}

There are various approaches which address the continuing demand in machine tools for an increase in productivity. One concept focuses on the reduction of idle time through increased speeds and accelerations, which requires lower masses in motion. Another method is the increase of process parameters, resulting in higher process forces that demand increased static stiffness to maintain tool deflection and workpiece quality. This creates a demand for components with a high stiffness to weight ratio or specific modulus as well as the use of materials with higher material damping. CFRP parts meet all the mentioned requirements and can

\section{Frederik Birk \\ f.birk@ptw.tu-darmstadt.de \\ Klaus Schützer \\ schuetzer@SCPM.unimep.br}

1 Institute of Production Management, Technology and Machine Tools, Technical University of Darmstadt, Otto-Berndt-Straße 2, 64287, Darmstadt, Germany

2 Lab. for Computer Integrated Design and Manufacturing, Methodist University of Piracicaba, Rodovia Luis Ometto (SP 306), Santa Bárbara d'Oeste, Piracicaba, 13451-900 Brazil contribute to increased dynamics as well as higher accuracy. The high potential of CFRP components as well as the need for the development of hybrid structures is discussed in [1]. Design approaches for high-speed machine tool structures, which take advantage of the high specific modulus, are presented in [2] and [3].

The combination of CFRP in hybrid structures, which exploit the different material potentials, is a classic approach in a lightweight design. A perfect example is the sandwich construction with CFRP face sheets and a polymer or aluminum core. Nevertheless, the main challenges regarding the integration of CFRP parts remain the same: the more complex design and manufacturing process as well as force application and joining, which is discussed in [4] and [5]. Given the variety of geometrical and mechanical requirements for machine tool structures, there is a need for a hybrid design, which is adaptive without compromising the benefits of CFRP. In general, hybrid structures and designs provide the challenge of new manufacturing and joining processes as described in [6]. This paper presents an innovative approach for a hybrid design consisting of mineral cast and CFRP as well as the corresponding metrological investigation. The approach focusses on improving the stiffness to weight ratio of the chosen demonstrator component. 
Fig. 1 a Basic assembly of reference machine tool. b TCP deviation due to acceleration of the elastic supported gantry. c Critical load case for the investigation of static stiffness. d Cross-section comparison of the steel and hybrid lightweight design

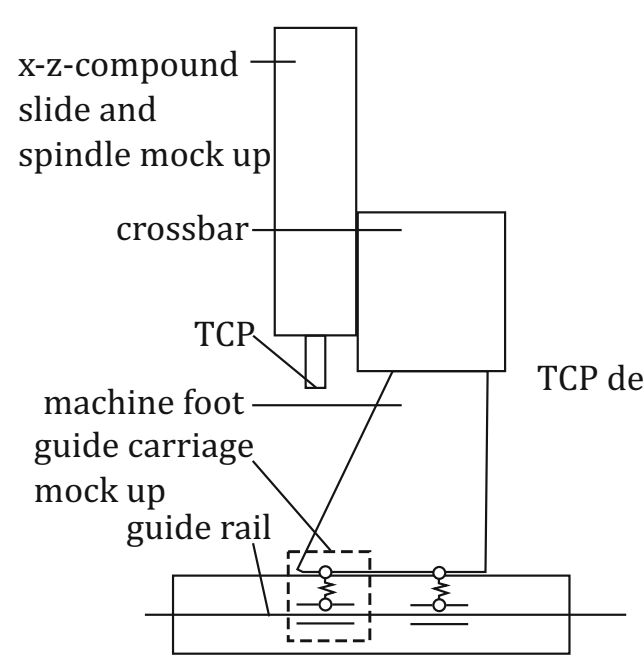

(a)

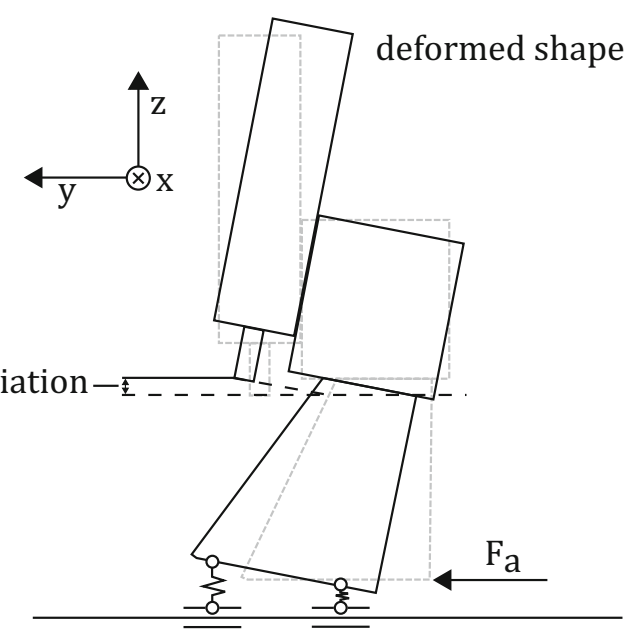

(b)

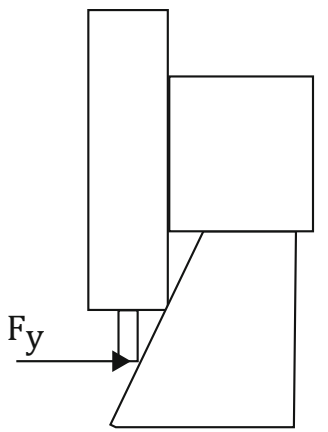

(c) steel design

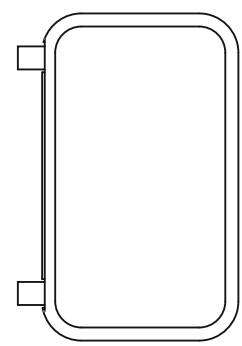

hybrid design

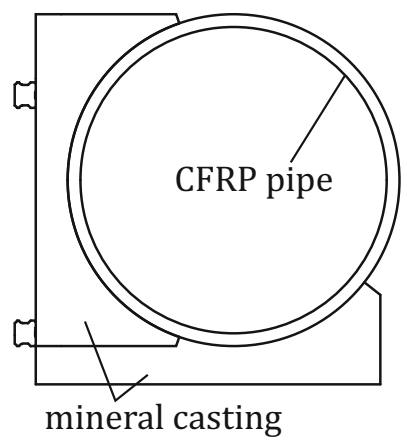

(d)

\section{Hybrid lightweight design}

The design of the reference machine tool is shown in Fig. 1a. Improving the stiffness to weight ratio for the new design can either be achieved by reducing the mass and/or increasing the static stiffness. As shown in [7], reduced mass improves the dynamic behavior by decreasing the tool center point (TCP) deviation during accelerations of the gantry. Increased static stiffness leads to a reduced displacement of the TCP due to process forces and enables

Table 1 Results of the numerical investigation of the reference steel design and the hybrid lightweight design

\begin{tabular}{lllll}
\hline Parameter & Unit & Steel & Hybrid & Deviation in \% \\
\hline Mass $m$ & $\mathrm{~kg}$ & 95.6 & 75.1 & -21.4 \\
Stiffness $c_{\mathrm{x}}$ & $\mathrm{N} / \mu \mathrm{m}$ & 1243.93 & 946.93 & -23.8 \\
Stiffness $c_{\mathrm{y}}$ & $\mathrm{N} / \mu \mathrm{m}$ & 33.86 & 34.14 & 0.8 \\
Stiffness $c_{\mathrm{z}}$ & $\mathrm{N} / \mu \mathrm{m}$ & 65.21 & 84.64 & 29.8 \\
\hline
\end{tabular}

The stiffness for each direction was determined with a load case in the same direction on a full-scale model and the interface between CFRP and mineral cast is modelled as bonded. The deviation is related to the reference steel design 
Fig. 2 Flow chart for the development process of the hybrid design

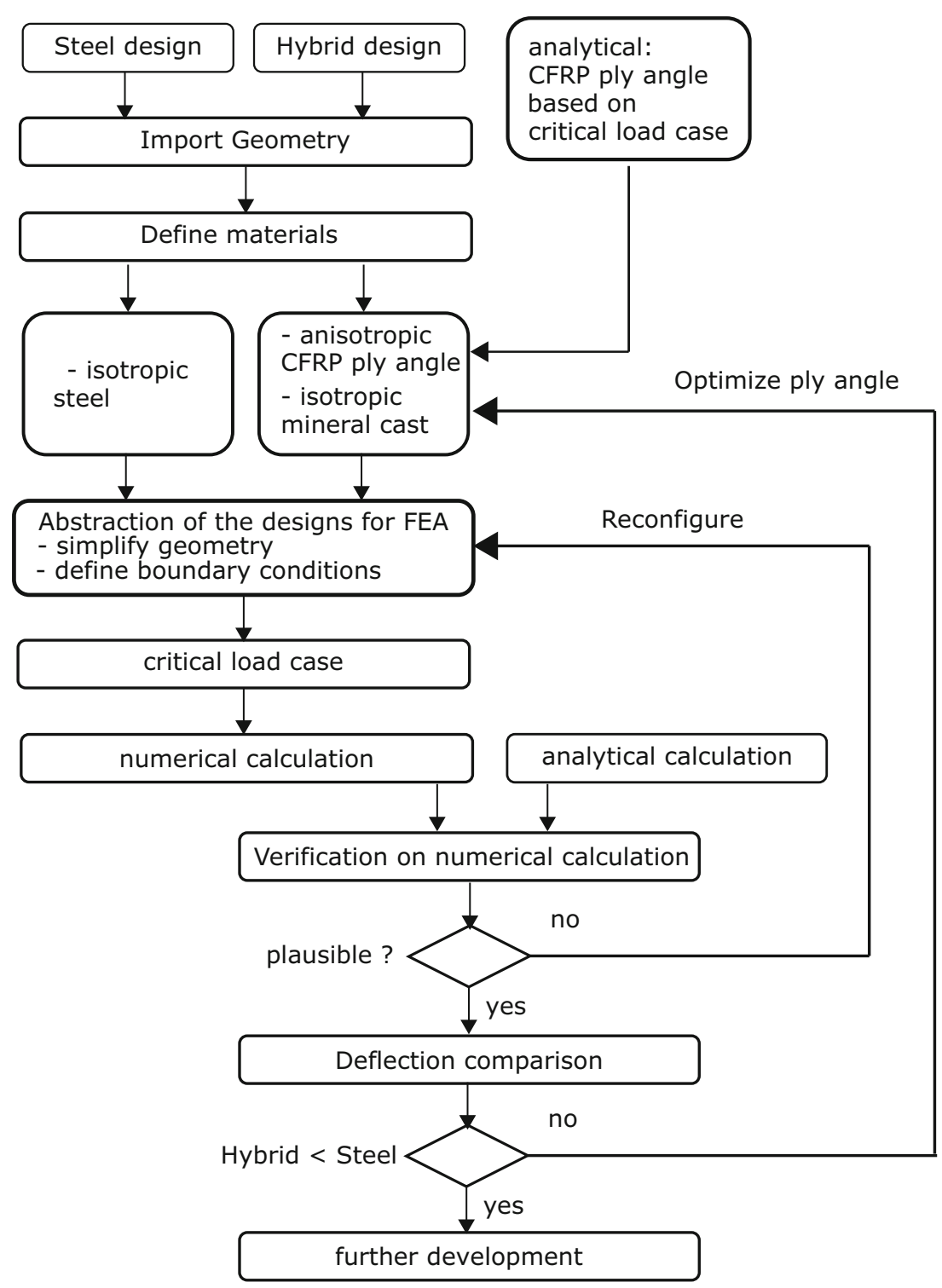

the reference steel design under dynamic load as shown in Fig. $1 \mathrm{~b}$ can be estimated as follows: crossbeam $25 \%$, y-axis guide rails $10 \%, \mathrm{x}$-z-compound $33 \%, \mathrm{z}$ - and $\mathrm{x}$-axis guide rails $13 \%$, additional components (housing, cables, etc.) $20 \%$. Crossbeam structures are less complex than the x-zcompound and were therefore chosen as a first demonstrator component for the CFRP-mineral cast hybrid design.

[7] and [9] show CFRP machine tool components, which have improved dynamic as well as static properties due to a high specific stiffness or stiffness to weight ratio. A similar approach, specifically designed for machine tool gantries, is presented in [10]. Nevertheless, the manufacturing complexity is significantly higher, a general problem for CFRP parts as described in [11]. The main reason is the high amount of manual work, which is especially needed 
Fig. 3 a Critical load case. b Boundary condition and kinematic coupling between TCP (force application point) and guide rails. c Side view of the deformed shape (scale factor 120, hybrid design). d Overview of the deformed shape (scale factor 120 , hybrid design)

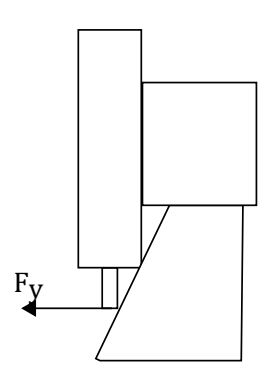

(a)

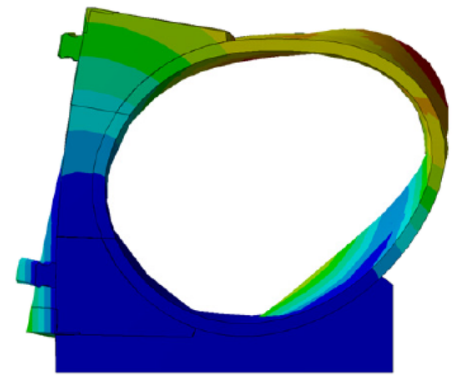

(c)

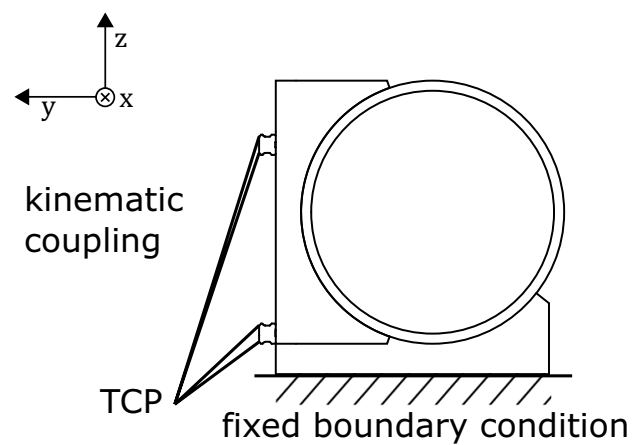

(b)

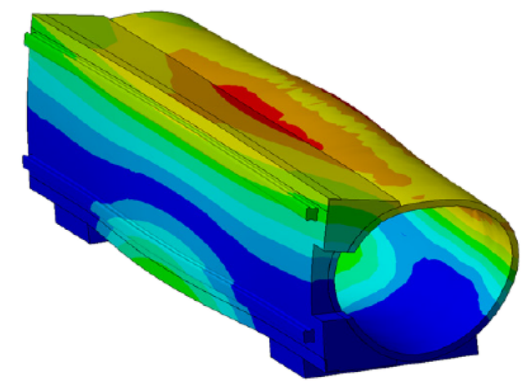

(d) to integrate force application points and interfaces to other parts.

Therefore, the basic idea for the hybrid lightweight design is to use premanufactured CRFP pipes or beams, which provide high specific stiffness, and combine them with mineral cast [12]. This material combination was used in [13] for various components of a table-top machine and provides several advantages. As well as CFRP, mineral cast provides higher material damping than steel or cast iron [14] and enables the direct implementation of mechanical interfaces [15]. The common epoxy base of CFRP and mineral cast simplifies the bonding process of the two materials at their interfaces. In addition, the integration of threaded sleeves into the mineral casting provides standardized interfaces for the connection to the machine feet and the guide rails. All these interfaces are integrated into the casting, therefore reducing the rework compared to the traditional steel design [16].

A comparison between the reference steel design and the new approach is shown in Fig. 1d and the corresponding mechanical properties are listed in Table 1. These are obtained by a numerical investigation (finite element
Fig. 4 a Exploded view of the components for the glued version. b Assembly

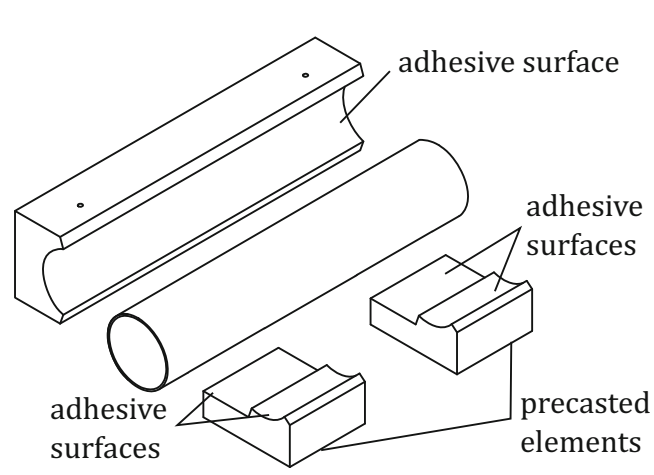

(a)

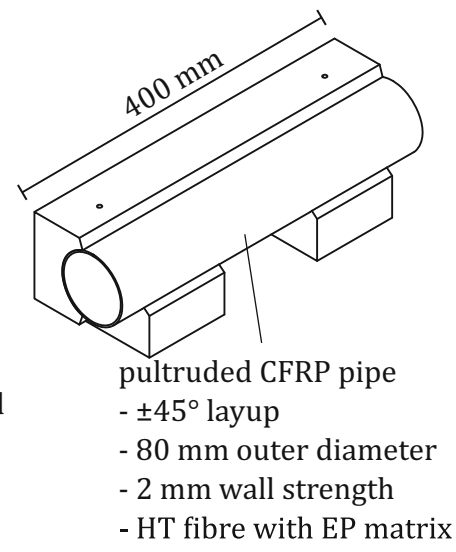

(b) 
method FEM) which shows that the static stiffness for the critical load case (see Fig. 1c) is nearly constant in comparison with the reference steel design (Table 1). The development process is shown in Fig. 2. The simulation model and the deformed shape for the critical load case are shown in Fig. 3.

As a conservative simplification, the interface between CFRP and mineral cast was modelled as bonded in the first step of investigation. The constant stiffness is achieved by increasing the geometrical moment of inertia and using a load specific layup for the CFRP pipe. The critical load case causes a torsional stress in the pipe. The best layup for this is $\mathrm{a} \pm 45^{\circ}$ balanced angle-ply laminate. In addition, the mass is reduced by $21 \%$. This increases the specific displacement by $26 \%$ from $0.64 \mu \mathrm{m} / \mathrm{kg}$ to $0.82 \mu \mathrm{m} / \mathrm{kg}$.

The further investigation focuses on the actual manufacturing process and the metrological investigation (static stiffness with and without additional thermal load) of the different manufacturing methods.

\section{Manufacturing methods and prototype production}

There are two proposed manufacturing methods for the mineral-cast-CFRP hybrid design, which are shown in Figs. 4 and 5. This adds another design element, in order to fine-tune the mechanical properties of the demonstrator component. The first approach is the use of three elements (the two connecting elements to the machine feet and the element for the CFRP pipe), which are cast first and then glued together and to the CFRP pipe with epoxy resin in one manufacturing step. A one-pieced mineral cast is also possible but complicates the bonding to the CFRP pipe, since the pipe must be fitted axially into the

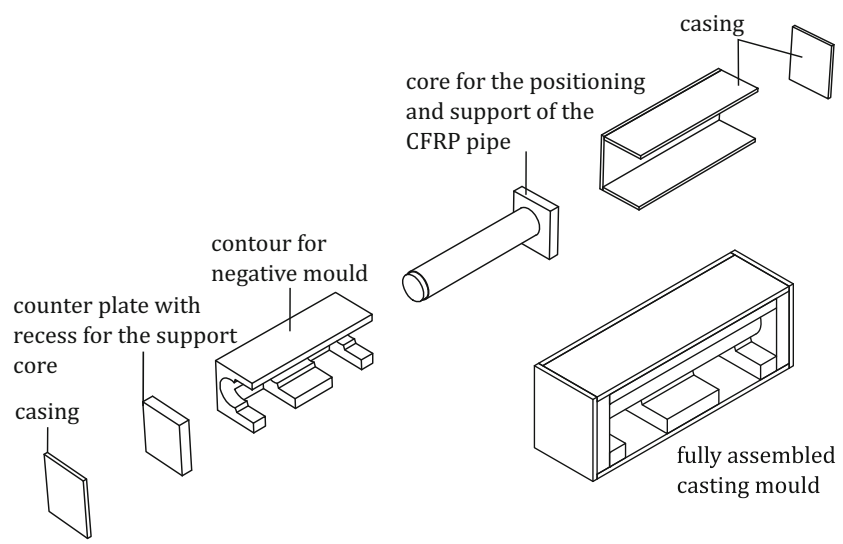

Fig. 5 Exploded view of the casting mold

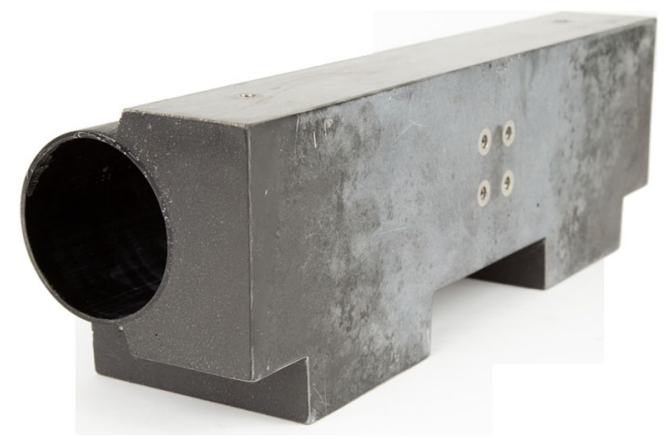

Fig. 6 Finished cast-in prototype

mineral casting. The chosen separating plane also provides an additional form fit between the precast elements, to support the adhesive film in case of shear loads. One disadvantage is the positioning during the bonding process, which can lead to relative misplacement between the precast parts, thus increasing the manufacturing complexity or demanding larger tolerances. For larger quantities, a gage can simplify the placement of the parts and ensure reproducible positioning.

Another challenge is the quality of the adhesive film. Therefore, the CFRP pipe is roughened and all surface areas are degreased to improve the wetting of the adhesive surface.

The second approach is the direct encasting of the CFRP pipe as shown in Fig. 5. Compared to the glued version, the manufacture and preparation of the molding are more complex because all parts have to be integrated and positioned relative to each other. The major advantage is that there is no additional rework needed after demolding the component.

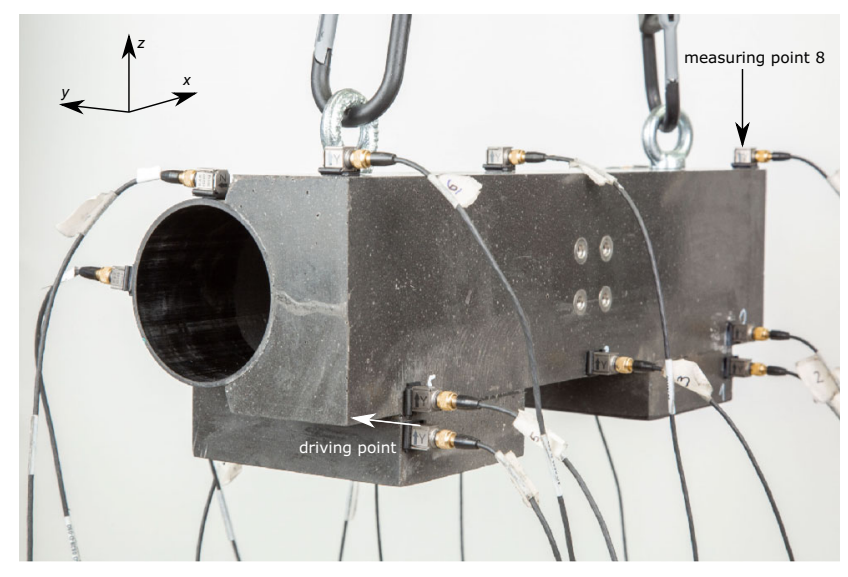

Fig. 7 Experimental setup for frequency response measurement. The component was suspended on the anchor points to imitate free boundary conditions [12] 

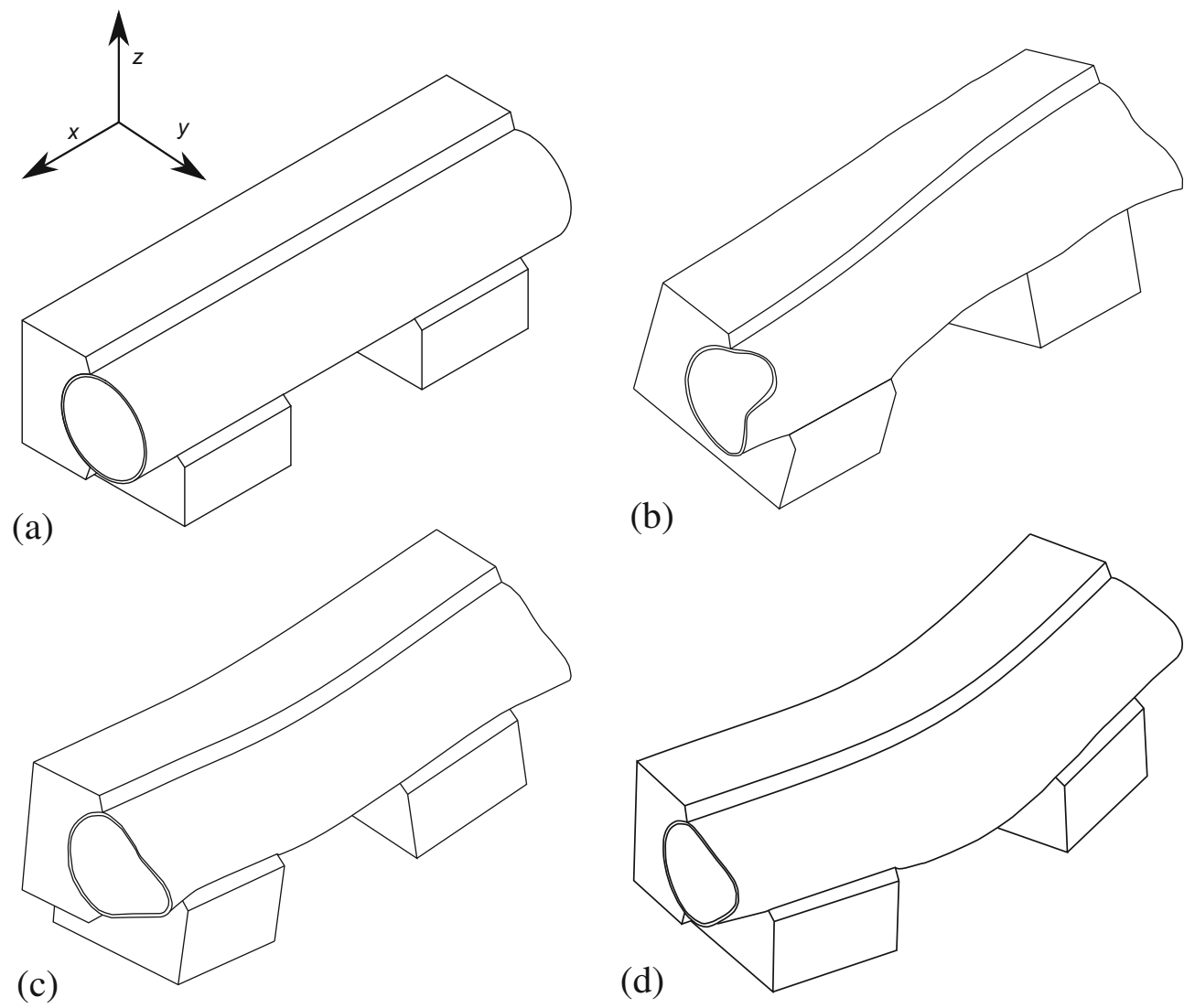

Fig. 8 a Undeformed shape. b $f_{1}$ : torsional mode x-axis glued: $1174 \mathrm{~Hz}$ cast-in: $1116 \mathrm{~Hz}$ deviation: $58 \mathrm{~Hz}$. c $f_{3}$ : bending mode y-axis glued: $1990 \mathrm{~Hz}$ cast-in: $1887 \mathrm{~Hz}$ deviation: $103 \mathrm{~Hz}$. d) $f_{2}$ bending mode z-axis glued: $1748 \mathrm{~Hz}$ cast-in: $1714 \mathrm{~Hz}$ deviation: 34 Hz [12]

In order to investigate the influence of the manufacturing methods, smaller scaled models (two for each method) of the machine tool gantry were manufactured. Figure 6 shows the cast mold model. There is a significant difference in the production time for these prototypes. Encasting the CFRP pipe takes $3 \mathrm{~h}$ including preparations, casting, and demolding. In comparison, the glued version takes
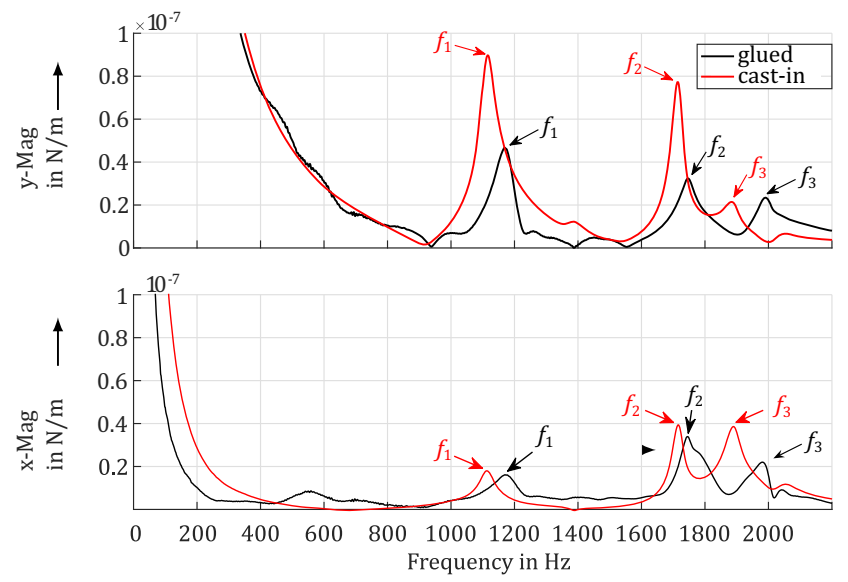

Fig. 9 Frequency response analysis comparison of the glued and cast-in demonstrators [12]
$10.5 \mathrm{~h}$ to be finished. The main reasons for the increased production time are the casting of three separate pieces and the positioning before the bonding.

\section{Dynamic behavior}

The detailed investigation of the dynamic behavior of the two different manufacturing methods was described in [12]. Figure 7 shows the experimental setup for frequency response analysis. The models are suspended on expander

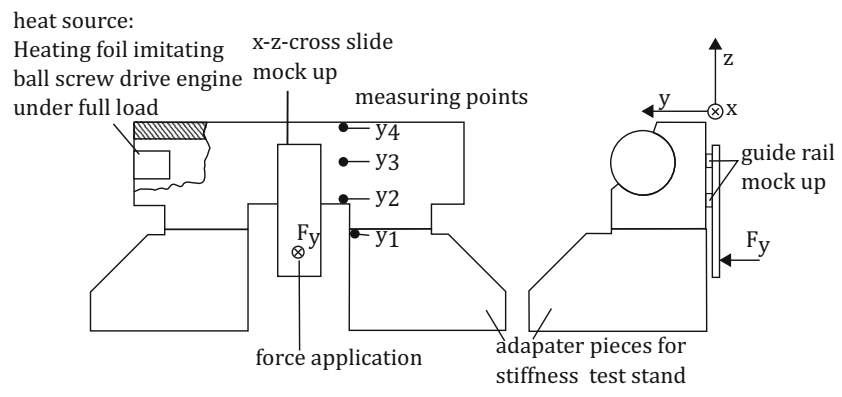

Fig. 10 Experimental setup for static stiffness test 
Fig. 11 a Comparison of the glued and cast-in models under quasi-static load. b Glued model with imperfection in the adhesive layer

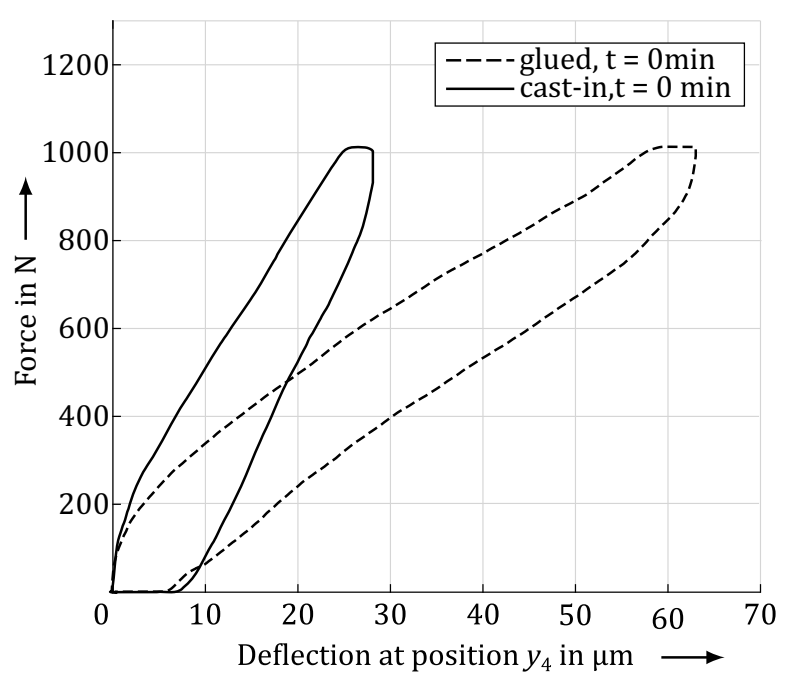

(a)

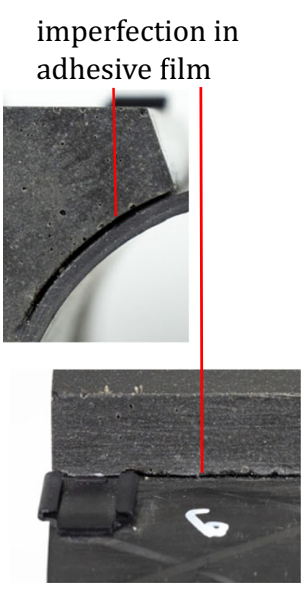

(b) ropes in order to create a soft suspension and free boundary conditions. The possible measurement points and mode shapes were determined in advance by a numerical investigation. The structures were induced ten times in y-direction to generate averaged frequency response functions. The response was measured with triaxial acceleration sensors. Due to the upper limit frequency of the frequency spectrum excited by the pulse hammer, the analysis of the compliance frequency response is limited to $2 \mathrm{kHz}$. Within this frequency bandwidth, the first three natural frequencies are examined. These eigenmodes are movement modes of the crossbar. The various eigenmodes of the CFRP tube, such as buckling eigenmodes, have no influence on the spindle-side eigenmodes of the crosshead. Since no large displacements were to be expected in the zdirection, only the $\mathrm{x}$ - and $\mathrm{y}$-directions were considered in the evaluation. In order to detect a shift of the eigenmodes in the frequency spectrum of both designs, the corresponding eigenfrequencies were compared. The evaluation of the compliance frequency responses of all measuring points showed that the first three natural frequencies of the bonded version in $\mathrm{x}$ - and $\mathrm{y}$-axis directions are higher than those of the cast construction. However, since both model variants have the same mass, it can be concluded that the bonded variant has a stiffer system behavior at least in the first three natural frequencies. These as well as the respective displacement of the natural frequency are shown in Fig. 8. Furthermore, the evaluation showed that the amplitudes of the first and second natural frequencies in $\mathrm{x}$ - and $\mathrm{y}$-direction are predominantly smaller with the glued construction method. This behavior can be explained by a high natural damping of the polymer adhesive layer. At the third natural frequency, the damping property of the adhesive layer could not be clearly evaluated. This can be explained by the fact that the third natural frequency is directly at the upper end of the excited frequency spectrum and thus the natural mode was not induced sufficiently.
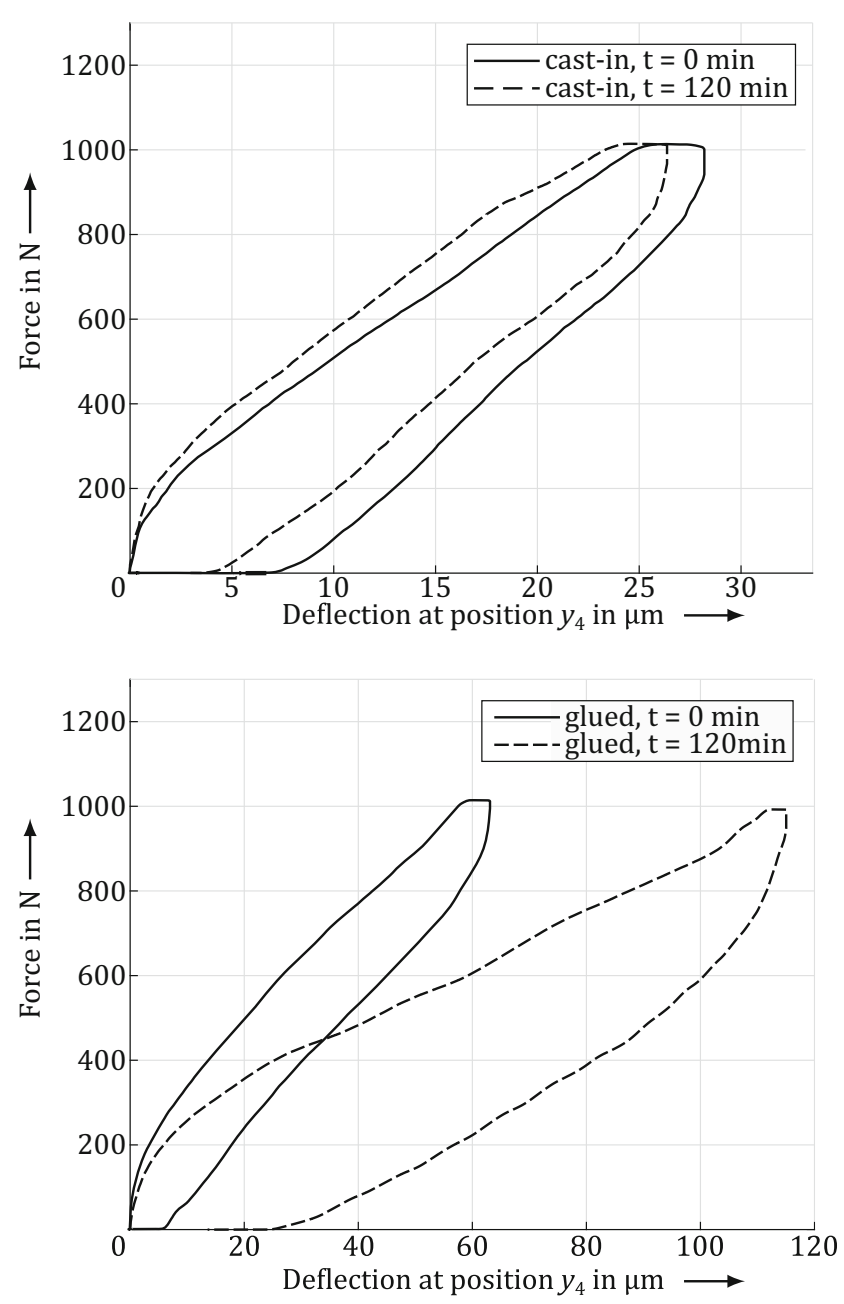

Fig. 12 a Comparison of the glued and cast-in models under quasistatic load. b Glued model with imperfection in the adhesive layer 
Table 2 Stiffness comparison between glued and cast-in prototype with effect of thermal load

\begin{tabular}{lr}
\hline Parameter & Stiffness in N/ $/ \mu \mathrm{m}$ \\
\hline Glued, $t=0 \mathrm{~min}$ & 16.11 \\
Glued, $t=120 \mathrm{~min}$ & 8.61 \\
Cast in, $t=0 \mathrm{~min}$ & 35.74 \\
Cast in, $t=120 \mathrm{~min}$ & 38.34 \\
\hline
\end{tabular}

The stiffness tests are conducted on scaled down models

Figure 9 shows the results of a frequency response analysis on measurement point 8 . The main observations in the $y$-direction are that the glued version shows higher damping as well as an increased dynamic stiffness compared to the cast-in version. The increased damping is stated by the lower magnitudes of the natural frequencies $f_{1}$ and $f_{2}$, which decrease by $53 \%$ and $55 \%$, respectively. Because of the mode shapes, this can be mainly seen in the y-direction. In addition, $f_{1}$ and $f_{2}$ are also slightly increased by $58 \mathrm{~Hz}$ and $34 \mathrm{~Hz}$, stating the higher dynamic stiffness of the glued version. The damping of the third eigenmode can be obtained in the frequency response function in the $\mathrm{x}$-direction. In general, the evaluation shows that the glued construction has a stiffer system behavior in $\mathrm{x}$ - and $\mathrm{y}$-axis direction and a higher damping of the first three eigenfrequencies These results show that the design of the interface between mineral cast and CFRP and the underlying manufacturing method alter the dynamic behavior of the compound and thus the machine component in a significant way.

\section{Static stiffness}

The investigation on static stiffness resembles the critical load case shown in Fig. 1c. A force of up to $1 \mathrm{kN}$ is applied with a pneumatic actuator, and the deflection is measured with laser displacement sensors at four positions $y_{1}$ to $y_{4}$. Figure 10 shows the experimental setup for the static stiffness investigation including the setup for thermal loads. The pneumatic actuator and the sensors are structurally decoupled to avoid reciprocal influence.

The corresponding force-deflection plots for the position $y_{4}$ are shown in Fig. 11a. The load cycle is repeated three times, and the mean value of the three deflections is evaluated. Both prototypes show a distinct hysteresis loading-unloading loop compared to a steel structure. An explanation is the higher material damping of the hybrid structure, especially due to the mineral cast as well as additional damping in the interfaces and joints. The castin version is $122 \%$ stiffer than the glued prototype. The
Fig. 13 Deflection at measurement positions. a Cast-in version at $t=120 \mathrm{~min}$. b Glued version at $t=0 \mathrm{~min}$. $\mathrm{c}$ Glued version at $t=120 \mathrm{~min}$

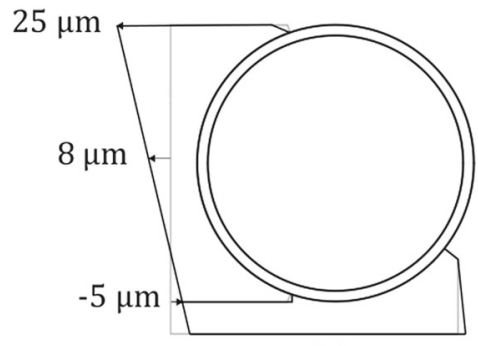

(a)

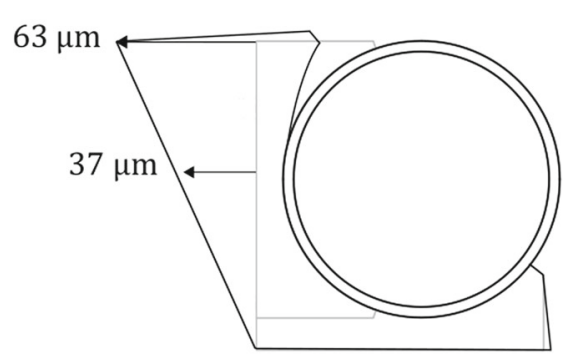

(b)

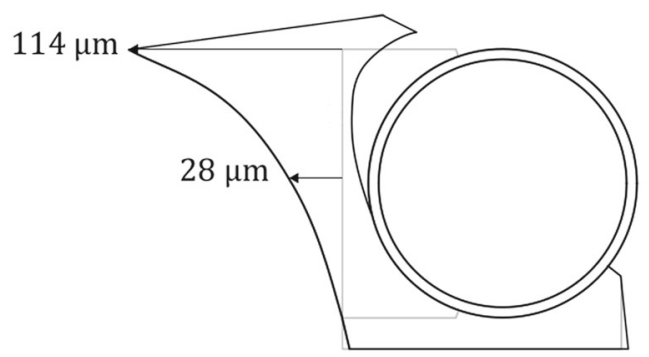

(c) 
adhesive film out of epoxy resin reduces the component stiffness significantly with its relatively small Young's and shear modulus. In addition, the force transmission from the mineral casting to the CFRP pipe and thus the stiffness of the interface depends on the surface area of the adhesive film [17]. Even small imperfections may lead to a significant stiffness decrease [18]. Since the prototype was hand-built, there are some areas without epoxy resin as shown in Fig. 11b, which contribute to a smaller stiffness.

\section{Static stiffness combined with thermal load}

Thermal loads are always of interest in machine tools, since they can affect the accuracy and lead to thermal stresses. The presented hybrid design consists of big parts of temperature-dependent plastic, which is why investigating the influence of thermal loads is especially significant. During the design process, a possible bimetallic effect between mineral cast and CFRP was taken into account. Mineral cast has a thermal expansion coefficient of $\alpha_{\mathrm{MC}}=15 \cdot 10^{-6} 1 / \mathrm{K}$ [19]. The in-plane thermal expansion coefficients for a $\pm 45^{\circ}$ balanced angle-ply laminate consisting of high tenacity fiber and epoxy resin can be estimated as $\alpha_{\mathrm{x}}=\alpha_{\mathrm{y}}=15 \cdot 10^{-6} 1 / \mathrm{K}$. Therefore, no thermal stress occurs along the $\mathrm{x}$-axis of the design, which is the most critical.

Figure 10 shows the experimental setup with a mock-up of the ball screw drive engine for the $\mathrm{x}$-axis. This mock-up is constantly set at $T=70^{\circ} \mathrm{C}$, which resembles the engine temperature under full load. The test runs for a total of $120 \mathrm{~min}$ and static stiffness tests are performed every $10 \mathrm{~min}$ (three load cycles for each stiffness test). Figure 12 shows the force-deflection plots at $t=0 \mathrm{~min}$ and $t=120 \mathrm{~min}$. The stiffness of the cast-in version compared to the glued one shows scarcely any difference under thermal load. The glued version almost loses half of its static stiffness under thermal load. This can be explained by the behavior of the interface between the CFRP pipe and mineral casting. The thermal load of the pure epoxy resin layer leads to a change in the adhesive behavior. The reasons for the change are the formation of sliding and expansion stress as a reaction to the temperature gradient. In addition, the elasticity of the epoxy resin layer increases with increased thermal stress [20].

Figure 13 shows a qualitative presentation of the deformation by evaluating the measurement positions $y_{2}$, $y_{3}$, and $y_{4}$. As listed in Table 2, the cast-in version shows nearly no deviation under thermal load. It is noticeable that the lower point is displaced in the negative direction. In comparison, in (b) the displacement is more significant at the upper two points of both versions. This suggests that the connection between mineral casting and CFRP pipe is flexible. The reason for this is the peeling load, which the adhesive layer can only absorb poorly. Through the load in the positive y-direction, the upper area in particular is subjected to tensile stress. This effect becomes even clearer under the influence of temperature, due to the decreasing stiffness. As an effect of the temperature influence over the period of time, the epoxy resin passes into the glass transition range $\left(T_{\mathrm{g}}=60^{\circ} \mathrm{C}\right.$ for the used cold setting resin system) and the mechanical properties decrease [21].

\section{Conclusion}

The presented hybrid lightweight design shows that it is possible to integrate CFRP parts into machine components with a reduced production complexity by recasting the CFRP element with mineral cast. In addition, the mechanical performance, especially the specific stiffness, can be improved significantly compared to traditional steel designs. The two presented manufacturing methods offer the advantage to fine-tune the machine characteristics for their specific applications. As shown, the glued version can improve the dynamic behavior by increasing damping and dynamic stiffness. On the contrary, the cast-in version shows improved static stiffness and is more robust regarding thermal loads. With these benefits and with regard to the simpler manufacturing process the cast-in version is considered the better option for hybrid structures out of CFRP and mineral cast. In general, the presented design approach is most beneficial if applied to relatively simple structures like beams because there is a broad variety of CFRP pipes and beams available. Further development should focus on the investigation of the operational stability of the interface of mineral cast and CFRP. A proposed metrological investigation is the stimulation of the demonstrator's natural frequencies combined with a reoccurring static stiffness measurement at certain load cycles. The results and conclusions from these tests will determine which manufacturing method shall be used for a full-scale prototype that can be metrologically compared to the reference steel design.

Acknowledgements This research project was funded and supported by the Federal Ministry for Economic Affairs and Energy - Germany within the ZIM project ZF4016515PO6.

Funding Information Open Access funding provided by Projekt DEAL. 
Open Access This article is licensed under a Creative Commons Attribution 4.0 International License, which permits use, sharing, adaptation, distribution and reproduction in any medium or format, as long as you give appropriate credit to the original author(s) and the source, provide a link to the Creative Commons licence, and indicate if changes were made. The images or other third party material in this article are included in the article's Creative Commons licence, unless indicated otherwise in a credit line to the material. If material is not included in the article's Creative Commons licence and your intended use is not permitted by statutory regulation or exceeds the permitted use, you will need to obtain permission directly from the copyright holder. To view a copy of this licence, visit http:// creativecommonshorg/licenses/by/4.0/.

\section{References}

1. Möhring HC, Brecher C, Abele E, Fleischer B (2015) Materials in machine tool structures. CIRP Ann Manuf Technol 64(2):725-748

2. Suh J, Lee D (2002) Composite machine tool structures for high speed milling machines. Annals of the CIRP 51(1):285288

3. Lee D, Suh J, Kim H, Kim J (2004) Design and manufacture of composite high speed machine tool structures. Compos Sci Technol 64:1523-1530

4. Camanho P, Lambert M (2006) A design methodology for mechanically fastened joints in laminated composite materials. Compos Sci Technol 66:3004-3020

5. Kim B, Lee D (2008) Characteristics of joining inserts for composite sandwich panels. Compos Struct 85:55-60

6. Roth S, Stoll M, Weidenmann KA et al (2019) A new process route for the manufacturing of highly formed fiber-metal-laminates with elastomer interlayers (FMEL). The International Journal of Advanced Manufacturing Technology 104:1293-1301

7. Landmann A (2018) Zur Gestaltung von Maschinenkomponenten aus Faser-Kunststoff-Verbund-Halbzeugen. PhD thesis, Technische Universität Darmstadt
8. Weck M, Christian B (2006) Werkzeugmaschinen 2 - Konstruktion und Berechnung. Springer, Berlin

9. Bretz A, Landmann A, Rost R (2014) Integration of carbon fibre reinforced structures in machine tools using the example of a swivel arm. Advanced Materials Research 1018:387-394

10. EEW PROTEC (2017) HSM Modal. www.eew-protec.de. Accessed 1 Dec 2017

11. Möhring H (2017) Composites in production machines. Procedia CIRP 66:2-9

12. Ali F, Birk F, Oeztuerk T, Abele E, Weigold M (2019) Hybrider Leichtbau in Werkzeugmaschinen. wt Werkstattstechnik online

13. Cho S, Kim H, Chang S (2011) The application of polymer composites to the table-top machine tool components for higher stiffness and reduced weight. Compos Struct 93:492-501

14. Kläger U (1995) Untersuchungen zum Einsatz von Mineralguß für Werkstückspannvorrichtungen in der spanenden Fertigung. PhD thesis

15. Orak S (2000) Investigation of vibration damping on polymer concrete with polyester resin. Cem Concr Res 30:171-174

16. Jackisch UV (2002) Mineralguss für den Maschinenbau. Verlag Moderne Industrie

17. Ewerszumrode A (1997) Einfluss der Abbindebedingungen auf das Eigenschaftsprofil geklebter Verbindungen aus fügeteilen mit unterschiedlichen Ausdehnungsoeffizienten. Tech. rep., Forschungsbericht des LWF Paderborn

18. Ewerszumrode A (2009) DIN EN 1465 Klebstoffe - Bestimmung der Zugscherfestigkeit von Überlappungsklebungen

19. Jackisch UV (2012) Maschinengestelle heute - nichts neues an der basis, oder? In: Maschinengestelle heute - werkstoffe konzepte innovationen, Wangener Maschinen Tage, Wangen, pp 10-23

20. Dietrich R (2018) Analyse der wärmeausdehnungsinkompatibilität bei Klebverbindungen aus Cfk Stahl und Aluminium bei der Fertigung einer lackierten Karosserie. $\mathrm{PhD}$ thesis, Technische Universität München

21. Schürmann H (2008) Konstruieren mit Faser-KunststoffVerbunden, 2nd edn. Springer, Berlin

Publisher's note Springer Nature remains neutral with regard to jurisdictional claims in published maps and institutional affiliations. 